Revista Eletrônica em Gestão, Educação e Tecnologia Ambiental Santa Maria, v. 20, n. 1, jan-abr. 2016, p. 254-265 Revista do Centro de Ciências Naturais e Exatas - UFSM ISSN : 22361170

\title{
Audiobooks como ferramenta pedagógica na educação inclusiva de deficientes visuais
}

\author{
Audiobooks as educational tool in inclusive education of the visually impaired \\ Maritê de Oliveira ${ }^{1}$, Liziany Müller Medeiros ${ }^{2}$, Ana Cristina da Fonseca \\ Ziegler ${ }^{3}$, Andréia L. Silva de Lima ${ }^{4}$ e Juliana Santos da Silva ${ }^{4}$ \\ ${ }^{1}$ Licenciada em Computação pela Universidade Regional do Noroeste , \\ 2Doutora em Agronomia, Departamento de Educação Agrícola e Extensão Rural, Universidade Federal de Santa Maria, Santa \\ Maria, RS, Brasil. \\ ${ }^{3}$ Graduanda em Engenharia Florestal, Departamento de Educação Agrícola e Extensão Rural, Universidade Federal de Santa \\ Maria, Santa Maria, RS, Brasil. \\ ${ }^{4}$ Mestranda em Tecnologias Educacionais em Rede, Universidade Federal de Santa Maria, Santa Maria, RS, Brasil. \\ ${ }^{5}$ Graduando em Agronomia, Universidade Federal de Santa Maria, Santa Maria, RS, Brasil.
}

\begin{abstract}
Resumo
A inclusão escolar pressupõe mais do que o direito a vaga em uma instituição de ensino regular, engloba o direito do aluno de obter alternativas pedagógicas diversas, de acordo com suas especificidades, que auxiliem no processo ensino-aprendizagem tornando-o sujeito na construção do seu saber. Pensando nas dificuldades dos alunos deficientes visuais que estão incluídos na escola regular e através de pesquisa, verificou-se o acesso restrito destes às obras literárias. Assim, os alunos do curso Técnico em Publicidade do Instituto Estadual Visconde de Cairu, de Santa Rosa, Rio Grande do Sul, formaram um grupo de estudo com o intuito de encontrar alternativas para preenchimento dessa lacuna. Surgiu a ideia de desenvolver livros falados a partir dos contos e histórias infantis, surgindo assim o Projeto Audiobooks. Ao longo deste foram feitas anotações, diários de campo e recolhidos materiais, para que cada etapa fosse devidamente documentada. O presente estudo busca apresentar o processo de desenvolvimento do Projeto Audiobooks, desde sua concepção inicial até a distribuição do material às escolas envolvidas. Espera-se fornecer subsídios para que projetos semelhantes sejam produzidos ou para que novas alternativas pedagógicas sejam pensadas, beneficiando os alunos especiais e contribuindo para a construção de um saber efetivo e da cidadania.
\end{abstract}

Palavras-Chave: Educação Inclusiva. Acessibilidade. Comunicação. Deficientes Visuais. Audiobooks.

\begin{abstract}
The school inclusion involves much more than the right to a place in an institution of regular education. It encompasses the right of the student to rely on various pedagogical alternatives, according to their specific characteristics to help in the teachinglearning process and become subject in the construction of knowledge. Thinking about the difficulties of visually impaired students being included in the regular school and as data gathered through research, it was found restricted access to literary works to the visually impaired. Thus students of the Curso Técnico em Publicidade from the Instituto Estadual de Educação Visconde de Cairu, Santa Rosa, Rio Grande do Sul, formed a study group in order to find alternatives to fill this gap. Came the idea of developing talking books from the tales and children's stories and thus was born Audiobooks Project. Throughout the project, notes, field diaries were being made and were being collected materials so that each step was documented. This study discusses the development process Audiobooks Project, from its initial conception to distribution of materials to schools in the area. It is expected to provide support for similar projects that are produced or that new pedagogical alternatives are designed, benefiting all special students and contributing to the construction of knowledge and effective citizenship.
\end{abstract}

Key-Words: Inclusive Education. Accessibility. Reading. Communication. Social Cleat. Visually Impaired. Audiobooks. 


\section{Introdução}

Uma sociedade permeada por justiça e igualdade pressupõe que todos os cidadãos, independente de suas especificidades, tenham o direito à participação e interação efetiva no contexto do qual fazem parte. Na perspectiva da inclusão escolar de alunos com necessidades especiais, isso significa dizer que, muito além de uma vaga em uma instituição de ensino regular, esses educandos possuem o direito de contar com alternativas que os auxiliem no processo ensino-aprendizagem, tornando-os sujeitos na construção de seu conhecimento.

Essa questão foi amplamente discutida no Curso Técnico em Publicidade do Instituto Estadual de Educação Visconde de Cairu, incitada, sobretudo, a partir da inserção de um aluno com deficiência visual na primeira série do ensino fundamental e a constatação da ausência de obras literárias faladas na biblioteca da instituição. Após investigação, verificou-se que essa situação se repetia em vários educandários da região Noroeste do Rio Grande do Sul, gerando dificuldades na inclusão efetiva de deficientes visuais e cegos no mundo literário e ao seu desenvolvimento.

Os alunos do curso técnico em Publicidade trouxeram essa problemática à pesquisadora, que formou um grupo de estudos em torno das dificuldades na inclusão efetiva de deficientes visuais no mundo literário. Uma das opções encontradas para amenizar esse cenário foi a construção de audiobooks, haja visto seu custo relativamente baixo aliado ao excelente potencial e a estrutura física que o curso possui, a serem disponibilizados às bibliotecas de escolas e bibliotecas públicas, contribuindo, dessa forma, para o acesso, permanência e sucesso no aprender desses alunos.

A proposta inicial do projeto, que recebeu o nome de "Projeto Audiobooks", foi transformar clássicos literários infantis impressos em livros em áudio e, posteriormente, foram incluídas obras da literatura gaúcha. A principal justificativa para realização do projeto está elencada na Declaração de Salamanca, uma resolução das Nações Unidas de 1994 que trata dos princípios, política e prática em educação especial e coloca que:

O princípio fundamental das escolas inclusivas consiste em que todos os alunos devam aprender juntos, sempre que possível, independentemente das dificuldades e das diferenças que apresentem. As escolas inclusivas devem reconhecer e satisfazer as necessidades diversas dos seus alunos, adaptando aos vários estilos e ritmos de aprendizagem, de modo a garantir um bom nível de educação para todos, através de currículos adequados, de uma boa organização escolar, de estratégias pedagógicas, de utilização de recursos e de uma cooperação com as respectivas comunidades. É preciso, portanto, um conjunto de apoios de serviços para satisfazer o conjunto de necessidades especiais dentro da escola (BRASIL, 1994).

Respeitando esse princípio e com o intuito de viabilizar a acessibilidade a literatura para deficientes visuais e cegos, extinguindo uma história de exclusão e segregação destes e buscando fortalecer o ideal de integração à rede regular de ensino, buscou-se a elaboração e desenvolvimento dos audiobooks para possibilitar o acesso desse público ao mundo da leitura e da imaginação.

Ao longo de todo o projeto, foram sendo feitas anotações, diários de campo e foram sendo recolhidos materiais, para que cada etapa fosse devidamente documentada. O presente estudo busca apresentar o processo de desenvolvimento do Projeto Audiobooks, desde sua concepção inicial até a distribuição do material às escolas da região. Espera-se fornecer subsídios para que projetos semelhantes sejam produzidos ou para que novas alternativas pedagógicas sejam pensadas, beneficiando todos os alunos especiais e contribuindo para a construção de um saber efetivo e da cidadania.

Visando cumprir o objetivo proposto, organizou-se o exposto em seis partes. A primeira, ou introdução, visa situar o leitor no assunto do estudo, bem como elencar seu objetivo e metodologia. A segunda traz um referencial teórico a respeito da educação inclusiva de alunos deficientes visuais e cegos e da importância da leitura para a construção do saber. A terceira apresenta a metodologia do 
presente estudo. A quarta seção traz a apresentação e discussão dos resultados, sendo que são elencadas todas as etapas de desenvolvimento dos audiobooks, bem como as potencialidades e dificuldades de cada uma. A quinta etapa expõe as considerações finais e a sexta apresenta as referências usadas ao longo do texto.

\section{Referencial teórico}

\subsection{Educação Inclusiva de Deficientes Visuais}

O termo deficiência visual engloba uma variedade de condições orgânicas que variam desde pequenas alterações na acuidade visual até a cegueira completa, caracterizada por uma classificação de zero a um décimo na escala optométrica de Snellen (Diagrama utilizado para avaliar a acuidade visual de uma pessoa. Wikipédia, a enciclopédia livre, 2013) ou por um campo visual reduzido a um ângulo menor que 20 graus. Logicamente, na maioria dos casos, quanto maior o grau de deficiência visual, maiores as implicações cotidianas para os sujeitos e seus familiares (LAPLANE; BATISTA, 2008).

De acordo com dados da Fundação Dorina Nowill para Cegos (Instituição filantrópica brasileira voltada à ampla integração dos deficientes visuais à sociedade. Wikipédia, a enciclopédia livre, 2013), o total da população brasileira, 23,9\% (45,6 milhões de pessoas) declarou ter algum tipo de deficiência. Entre as deficiências declaradas, a mais comum foi à visual, atingindo $3,5 \%$ da população. Em seguida, ficar am problemas motores $(2,3 \%)$, intelectuais $(1,4 \%)$ e auditivos $(1,1 \%)$.

Ainda, a cada 5 segundos uma pessoa se torna cega no mundo. Desses, 90\% ocorrem nos países emergentes e subdesenvolvidos. Estudos revelam que até 2020, o número de deficientes visuais poderá dobrar no mundo.

De acordo com LAPLANE e BATISTA (2008), embora algumas pesquisas indiquem alguns atrasos em aspectos do desenvolvimento de deficientes visuais em relação à indivíduos que enxergam normalmente, a plasticidade cerebral e as experiências de vida são capazes de mudar esse cenário e, ao chegar à adolescência, podem não haver mais diferenças. Os autores destacam que a superação de eventuais atrasos relaciona-se, diretamente, às experiências sensoriais, motoras e sociais dos indivíduos, bem como aos estímulos do ambiente no qual estão inseridos.

VIGOTSKY (ANO), em seus estudos, coloca que existem dois tipos de deficiência: a primária e a secundária. A primeira relaciona-se a limitações orgânicas, ou seja, engloba os componentes biológicos das pessoas. Já a segunda diz respeito às consequências psicossociais da deficiência e relaciona-se ao meio social no qual está inserida, bem como às limitações que a falta de estímulos pode acrescentar à deficiência primária.

A deficiência secundária, portanto, aumenta quando em ambientes como a escola, por exemplo, existem formas de segregação às pessoas que não se enquadram nos ditos padrões de normalidade impostos pela sociedade (NUERBERG, 2008).

A visão é uma função altamente motivadora para o desenvolvimento em todos os seus aspectos: os objetos, as pessoas, as formas, as cores e o movimento despertam curiosidade e interesse e incitam a criança a se aproximar e explorar o mundo exterior. Crianças com baixa visão ou cegueira podem ter esse interesse diminuído pela falta de estímulos e podem, assim, tornar-se apáticas e quietas. Por isso, é preciso que o ambiente seja organizado para promover ativamente o desenvolvimento por meio dos canais sensoriais que a criança possui, de modo tal que ela seja capaz de participar nas atividades cotidianas e de aprender como qualquer criança (LAPLANE; BATISTA, 2008, p.214).

Uma educação de qualidade é um objetivo que pode ser alcançado por todos, crianças com e sem deficiências ou limitações, mas, para tanto, são necessários meios adequados para superação das diferenças. A escola precisa utilizar todos os recursos disponíveis, além de sempre buscar novas 
ferramentas, para que todos os alunos encontrem condições semelhantes de aprendizagem (SANTOS; SILVA, 2013).

\subsection{A importância da leitura para construção do conhecimento}

As histórias e contos infantis constituem fontes de sabedoria e possuem um importante papel na formação da identidade dos indivíduos. Há algum tempo, elas foram redescobertas como ferramentas de construção do conhecimento, tornando-se recursos ímpares no cenário da educação, sobretudo nas séries iniciais. Elas se tornam ainda mais relevantes no sentido em que, atualmente, entende-se ser fundamental que as crianças não apenas se alfabetizem, mas que vivenciem, de forma plena, o processo de letramento.

O conceito de letramento diz respeito a uma alfabetização que ultrapassa a aprendizagem do sistema alfabético e engloba a aprendizagem dos usos sociais e culturais desse sistema. Uma pessoa letrada não apenas lê e escreve, mas conhece os signos linguísticos, seus significantes e consegue fazer uso social e cultural desse sistema (SOARES; 2009; COELHO; CASTRO, 2010). Uma vez que espera-se que a escola constitua um ambiente alfabetizador e um local de ampliação do letramento dos educandos, não poderia ser diferente para alunos com deficiência visual.

Através da leitura de histórias infantis, sobretudo contos, também se desenvolvem atitudes de cidadania, como convívio em sociedade e comportamentos éticos. Isso porque, os enredos são permeados por situações ligadas a valores universais, como justiça, amizade, soliedariedade, entre outros. Além disso, também são expressos sentimentos como inveja, raiva, traição, covardia, desigualdade. Há espaço, portanto, para que seja feita toda uma discussão em torno dos valores morais. Ainda, há possibilidade de que os comportamentos adotados pelos distintos personagens constituam oportunidade de reflexão, desenvolvendo o espírito crítico das crianças (SOUZA; BERNARDINO, 2011).

RIGLISKI (2012) acrescenta que é fundamental que a criança, ao longo do processo de desenvolvimento infantil, descubra sozinha como resolver seus problemas e se descubra como indivíduo capaz de aprender, já que vive em uma sociedade repleta de desafios a serem superados. Ouvindo histórias, é possível que o aluno tenha suas curiosidades respondidas e consiga encontrar novas ideias para resolver questões de seu cotidiano, agregando outras regras, outra ética, outra ótica. Esse pensamento está de acordo com o exposto por SOUZA e BERNARDINO (2011, p. 214), quando defendem que:

A comunicação por meio da narração de histórias fala as crianças mais profundamente do que a linguagem literal, a linguagem do pensamento; dramatizar com bonecos ou fantoches, representando aquilo que se quer dizer através do desenho ou pintura é fazer uso da linguagem imaginativa, essa é naturalmente a linguagem infantil. Nas histórias, o mal está tão presente quanto o bem, existem inúmeros obstáculos a serem vencidos, aparecendo escolhas de solução que permitem que a vitória aconteça. Todos esses aspectos fazem parte da vida psíquica da criança, formalizando o processo de identificação.

Por tudo isso posto, é necessário perceber a história infantil como recurso pedagógico, repleto de benefícios para que a criança otimize seu processo de construção do conhecimento. Para uma criança com deficiência visual os benefícios da literatura infantil são os mesmos e, do mesmo modo, ela deve ter contato com as histórias desde muito cedo, para que seu desenvolvimento seja pleno. Os audiobooks, nesse sentido, constituem uma alternativa muito interessante, pois podem permitir que os indivíduos se insiram no mundo literário antes mesmo de aprenderem a linguagem Braille.

O país que mais produz audiobooks no mundo é a Alemanha, país no qual esses recursos não são utilizados somente por aqueles que possuem deficiência visual, mas pela população em geral. No Brasil os primeiros audiolivros surgem na década de 70, mas, ao contrário dos alemães, os brasileiros não possuem o costume de escutarem audiolivros. Obras nesse formato são mais usadas por 
deficientes visuais o que, de certa forma, restringe a divulgação de novos títulos (MENEZES; FRANKLIN, 2008). Além disso, as obras para crianças, de acordo com pesquisa em sites de editoras, estão mais voltadas para aquelas com idade um pouco mais avançada, sendo que contos infantis não são comumente produzidos. Destaca-se algum trabalho nesse sentido de fundações filantrópicas, como a Fundação Dorina Nowill, que possui alguns audiobooks de livre acesso disponíveis.

\section{Metodologia}

O presente estudo foi desenvolvido a partir dos diários de campo e das anotações e pesquisas realizadas ao longo do desenvolvimento do "Projeto Audiobooks", dos alunos do curso Técnico em Publicidade do Instituto Estadual de Educação Visconde de Cairu, de Santa Rosa - RS. Durante todo o percurso do projeto foram sendo reunidas informações, documentos e fotos do trabalho que estava sendo desenvolvido, já com o intuito de, no futuro, repassar a outros interessados na inclusão escolar um roteiro de construção de um modelo pedagógico a ser reproduzido ou aprimorado em prol de crianças com necessidades especiais.

Além de documentos pessoais, para a construção do presente exposto foram consultados artigos pesquisados em bancos de dados científicos, tais como Google Acadêmico, Scielo, Redalyc e EduBase, entre outros, além, de livros de literatura corrente e livros de referência. Não houve delimitação de data para a pesquisa de materiais e foram utilizadas as palavras-chave "inclusão", "deficiência visual", "literatura infantil", "histórias infantis" e "construção do conhecimento", de forma combinada.

Após a obtenção, o material passou por uma etapa de avaliação, na qual se realizou uma leitura prévia de cada um dos textos, a fim de aferir se o conteúdo poderia, realmente, contribuir para a discussão do tema proposto. Foram excluídos aqueles cujo teor se distanciava do foco da pesquisa e o restante dos textos foi submetido à próxima etapa, que consistiu na leitura aprofundada e fichamento do material, realizado em fichas manuais. Posteriormente, o material passou pela fase de leitura e interpretação, que culminou na redação do texto final, cujo resultado encontra-se no presente exposto.

\section{Apresentação e discussão dos resultados}

\subsection{Desenvolvimento da ideia inicial}

A referida pesquisa, como já posto, partiu da constatação da dificuldade de participação ativa de um aluno cego, matriculado no ensino fundamental do Instituto Estadual de Educação Visconde de Cairu, nas aulas onde se trabalha a literatura infantil como um dos recursos para a alfabetização. Considerando a possibilidade da realização de um projeto que viesse a oportunizar a inclusão efetiva do referido aluno no Ensino Regular, bem como dispor de material para futuras pesquisas de outros alunos nas mesmas condições, os alunos do curso Técnico em Publicidade iniciaram um grupo de estudo, no qual realizaram pesquisas a respeito da dificuldade de inserção de deficientes visuais no mundo literário.

Os estudos iniciais giraram em torno de como a legislação abordava o indivíduo com deficiência no ambiente escolar. Foram lidos e discutidos documentos como Declaração dos Direitos Humanos, Declaração Universal dos Direitos dos Deficientes, Constituição Federal do Brasil, Estatuto da Criança e do Adolescente e Declaração de Salamanca. Todos esses textos possuíam em comum o fato de citarem a educação como direito e colocarem que essa deve ser realizada de acordo com as condições do indivíduo, com equiparação de condições e sem exclusão.

Partindo disso, os integrantes do grupo de pesquisa compreenderam que a educação dos indivíduos com e sem deficiência possui exatamente os mesmos objetivos e, portanto, alunos que enxergam ou aqueles que possuem deficiência visual devem ter as mesmas oportunidades. $\mathrm{O}$ que 
deve mudar são os caminhos que cada um desses alunos trilha para chegar ao mesmo ponto. Ou seja, aqueles que possuem deficiência necessitam de vias alternativas de construção do conhecimento, pois suas necessidades educacionais são específicas.

Quando essas reflexões foram feitas, logo no primeiro encontro do grupo, cabe destacar o quanto geraram debate por parte dos alunos participantes. Eles questionaram muito o fato de que forma uma criança, que não vê como as demais crianças pode construir significados em torno de palavras e de conceitos que são ensinados e aprendidos no cotidiano escolar. Uma das alunas inclusive citou como exemplo a história dos Três Porquinhos e questionou como um deficiente visual deve conceber um porquinho ou um lobo, sem nunca tê-los visto. Outro aluno destacou que a questão era ainda mais profunda, pois muitas crianças nem sequer conheceriam a história, já que não poderiam lê-la como os demais e os livros em braile nem sempre estavam disponíveis.

A própria inclusão foi alvo de discussões, pois, alguns dos alunos colocaram que a escola simplesmente receber as crianças nos bancos escolares não era, de forma alguma, efetivamente incluílas. Isso está de acordo com o exposto por JESUS $(2007$, p.3), que destaca:

[...] incluir um cidadão é muito mais que oferecer um espaço adaptado fisicamente à especificidade de sua limitação. É acreditar na força transformadora existente em cada ser humano e, mais ainda, é fazê-lo acreditar na existência dessa força. É olhar para uma criança na tenra idade e, independente de sua limitação, aceitar que ela é o ser cognoscente teorizado por Piaget, aquele que não está alheio ao mundo e que busca a todo instante compreender os fatos que cercam sua existência e que ele pode e deve protagonizar, intervir, modificar sua vida, sua história [...].

A partir da temática inclusão, comecou-se uma discussão a respeito do que poderia ser feito para melhorar q vivência escolar do aluno com deficiência visual, bem como alavancar sua construção do saber. Vários livros e artigos foram lidos e discutidos e, em um deles, um dos alunos destacou um trecho a respeito do encantamento promovido por contos infantis nas crianças:

Esses contos, quando éramos crianças, nos introduziram num universo encantado cuja admirável magia nos permitiu dar impulso à nossa imaginação cada vez que as dificuldades da vida real ameaçavam nos abater [...] as esperanças mantidas pelos contos de fada, nos permitiam superar corajosamente as adversidades, fossem elas reais ou imaginárias [...]. Os contos de fada graças à sua imensa variedade de acontecimentos e situações, graças às suas ricas - e muitas vezes ricas demais - descrições de prazeres, nos permitiram tecer à sua imagem fantasias otimistas que nos arrancavam de um mundo no qual estaríamos bem mais descontentes de habitar (BETTLHEIM, 1980, p. 7-9).

Quando o grupo leu esse trecho do livro, todos concordaram que impulsionar a leitura de histórias infantis entre as crianças com deficiência visual é algo com o qual queriam trabalhar. Isso porque, essas crianças vivenciam um cotidiano que, por si só, é complexo e, desse modo, a literatura infantil tem potencial de auxiliar, não só a construção do conhecimento, mas também de amenizar situações complicadas, através de artifícios imaginativos e do poder compensatório da fantasia (RESENDE, 2007).

A partir do cenário investigado, efetuou-se uma busca no acervo bibliográfico da instituição, onde está incluído o aluno cego, constatando que não havia nenhum livro que oferecesse a acessibilidade de informação, isto é, em Braille ou livro falado, para que a professora, aluno e família viessem a se beneficiar deste recurso no processo ensino aprendizagem, nas séries iniciais do Ensino Fundamental, levando-se em consideração de que a literatura infantil faz com que os alunos, nesta faixa etária, vivam num mundo imaginário do faz de conta, ampliando seu vocabulário, para posteriormente desenvolver a escrita, assimilando com mais prazer e paixão o mundo das letras.

Os alunos perceberam que havia uma lacuna importante, que precisava ser preenchida e, juntos, começaram a discutir de que forma tornar a literatura infantil mais acessível para alunos com deficiência visual. Várias ideias foram sendo desenvolvidas, mas uma foi recebida com maior entusiasmo e logo se tornou a preferida de todos: a criação de livros falados de histórias infantis. Um 
dos participantes sugeriu que eles fossem denominados audiobooks e que o grupo se reunisse uma vez na semana para desenvolvê-los. Nascia assim o Projeto Audiobooks, que foi desenvolvido ao longo de todo o ano de 2012.

\subsection{Desenvolvimento do Projeto Audiobooks}

Uma vez que os alunos elencaram o que queriam fazer, o Projeto Audiobooks começou a tomar forma e, em um primeiro momento, foram feitas pesquisas sobre quais eram os insumos necessários para que os livros falados fossem gravados. Profissionais da área da edição de áudio foram procurados, assim como outros professores do curso e todo o rol de conhecimentos oriundos do próprio Técnico em Publicidade foi mobilizado. Foram, ainda, consultados alguns professores de Educação Especial, para que fossem verificadas possíveis regras para gravação dos áudios.

Para gravação de um audiobook, de acordo com informações coletadas pelos alunos, é preciso que o narrador tenha uma voz clara, bem articulada e saudável, que saiba trabalhar articulação, entonação, inflexão e ritmo. A velocidade da fala deve ser equilibrada: nem muito rápida para não dificultar a compreensão, nem muito lenta, para não se tornar monótona. Além disso, devem ser preservadas as frases exatas escritas pelo autor do livro original, para que não se configure plágio. Ainda, optou-se pela gravação de todos os livros de um mesmo autor por um mesmo ledor, para que os alunos conseguissem identificar obras pela voz, criando uma identificação.

Verificou-se que o estúdio de gravação, bem como o laboratório de edição presentes na Instituição de Ensino eram suficientes para todo desenvolvimento do projeto. Os participantes começaram, então, a estudar com afinco como desenvolver todo processo de produção e, quando estavam com o roteiro de trabalho concluído, começaram uma seleção das obras que seriam gravadas.

Para essa seleção, foram consultadas professoras de educação infantil e séries iniciais do Ensino Fundamental, que destacaram algumas obras literárias infantis pelas quais as crianças possuíam predileção. Além disso, entre os alunos, houve troca de ideias, possibilitando, desta forma, a participação de cada um na elaboração do projeto e na seleção de obras literárias infantis que viessem a contemplar o aprender do aluno cego, de maneira mais lúdica e prazerosa, oportunizando a inclusão do mesmo na sala de aula e nas atividades extra classe, orientadas pela professora regente da turma.

Uma vez escolhidas as obras a serem gravadas em áudio, os alunos do Curso Técnico em Publicidade fizeram a leitura das mesmas, treinando as entonações de voz e dividindo os diálogos, de modo a tornar a história contada no audiobook o mais realista possível, para que mesmo sem auxílio de figuras, os alunos com deficiência visual pudessem desenvolver sua imaginação, sua capacidade expressiva, sua curiosidade de vida e tivessem o mesmo encantamento que os livros infantis proporcionam às crianças sem deficiência.

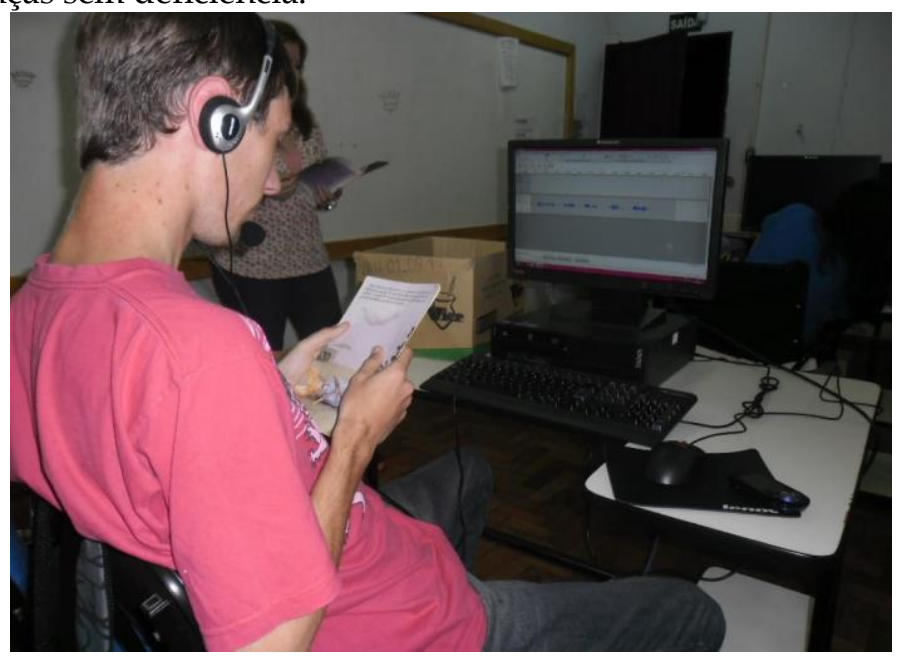

Figura 1 - Alunos do Projeto Audiobooks estudando as obras literárias antes das gravações Fonte: Arquivo pessoal da pesquisadora. 
MENEZES e FRANKLIN (2008) destacam que os audiobooks ou audiolivros devem transmitir sentimentalismo nas apresentações, a partir da sonorização. Transmitir sentimentos através da voz não foi algo simples e demandou um esforço conjunto por parte de todos os participantes. Foi visível o empenho com que cada um trabalhou para que as narrações fossem feitas da melhor maneira possível para beneficiar aqueles que às receberiam.

Após reunirem-se durante algumas semanas para ensaios e realizarem alguns testes em estúdio, os alunos se reuniram para a gravação do primeiro CD no estúdio da instituição, que foi a história "Peter Pan". No fim do trabalho todos ficaram muito satisfeitos com o trabalho e combinaram que continuariam com os ensaios de outras obras e que gravariam um CD por semana, para completar uma pequena coleção que seria doada, num primeiro momento, para a escola onde o projeto havia sido desenvolvido e depois para outras escolas onde há alunos com deficiência visual.

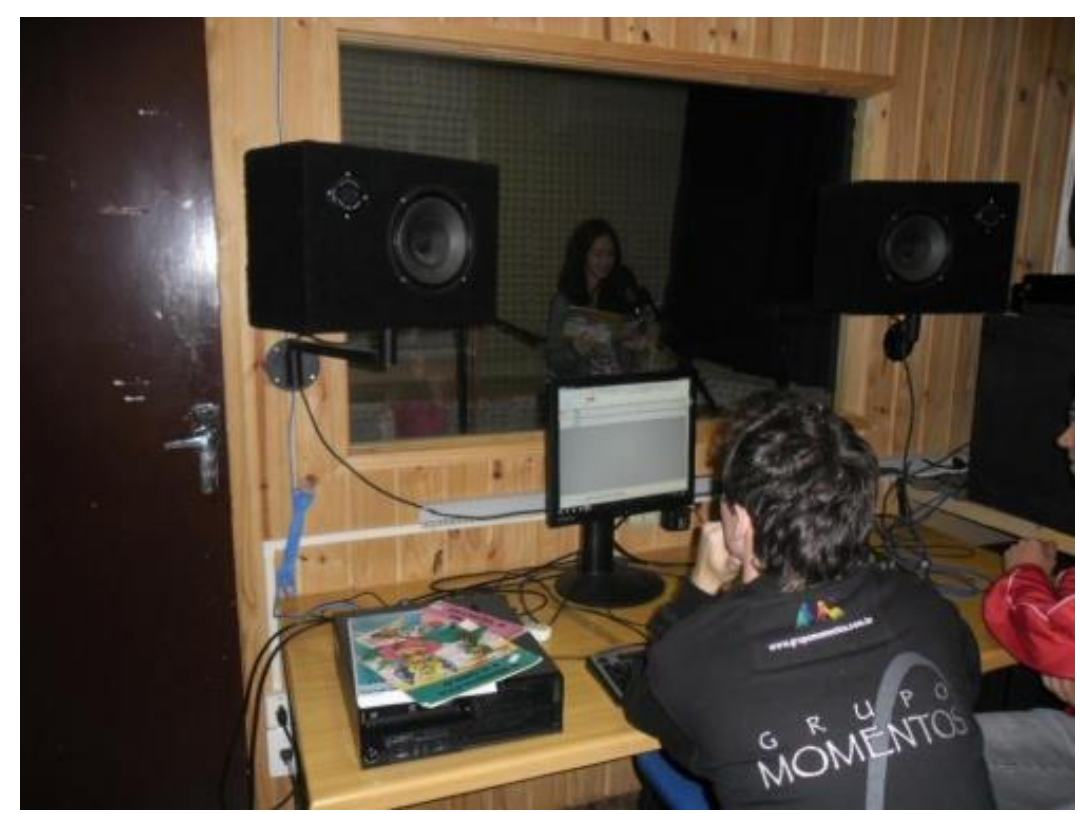

Figura 2 - Alunos gravando primeiros audiobooks

Fonte: Arquivo pessoal da pesquisadora.

A cada semana que os audiobooks eram gravados, os alunos iam incrementando suas dublagens, as entonações iam ficando mais bem construídas e os CDs ficavam cada vez melhores, mostrando o interesse de todos em fazer o melhor trabalho possível para as crianças. Quando chegaram ao número de $20 \mathrm{CDs}$ gravados, os alunos decidiram encerrar a primeira coleção e cada uma das gravações foi testada e então feita uma capa em Braille para que quando tivessem conhecimento desta linguagem as crianças pudessem ter autonomia de escolher seus próprios CDs.

Durante todo o projeto teve-se a preocupação com a sustentabilidade, pois, a impressão de um livro em Braille necessita de uma grande quantidade de papel, ao contrário dos audiobooks, que são em CDs.

\subsection{A distribuição dos CDs e a ampliação do Projeto Audiobooks}

Após a gravação dos audiobooks, os CDs foram fornecidos à biblioteca da Instituição de Ensino onde foram desenvolvidos e, posteriormente, à escola de educação especial do município, que desenvolve um trabalho com alunos deficientes visuais. No mês de agosto do ano de 2012, os alunos encaminharam o Projeto Audiobooks à Mostra de Educação Profissional (MEP), realizada em Palmeiras 
das Missões. Na MEP, o projeto foi premiado com o troféu destaque no eixo tecnológico produção cultural e design e também obteve a nona classificação geral.

\section{Projetos de Pesquisa do Cairu são premiados em Mostra}

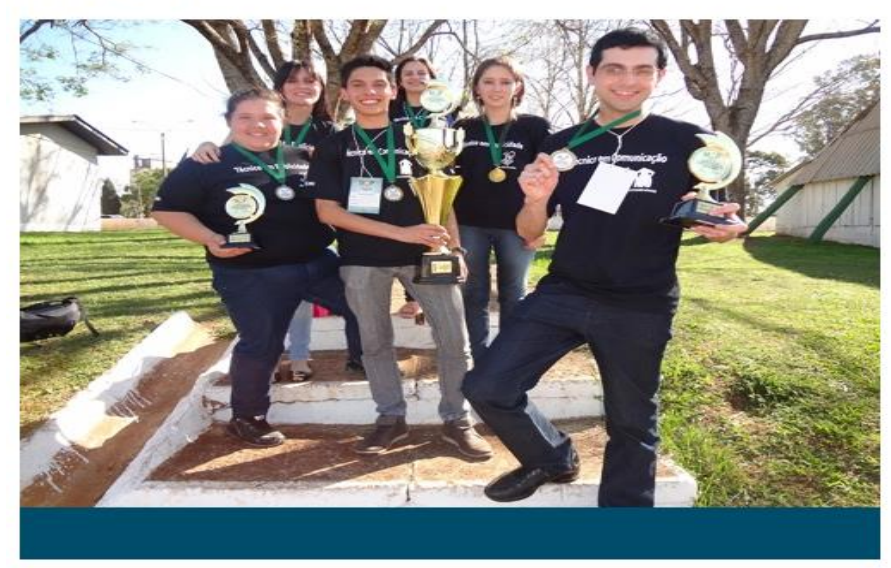

Com grande prestígio popular, o projeto "Audiobooks", desenvolvido pelo curso técnico em publicidade tem perspectivas de ampliar a proposta de produção de livros falados para alfabetização de cegos. A ideia é que as escolas possam atender às necessidades indusivas e educacionais de alunos com deficiência visual cega. 0 projeto, orientado pela professora Maritê Oliveira e com coorientação da professora Ivete Correa, estimulou a sensibilidade aos temas "acessibilidade à in formação" e "educação indusiva". Com isso, ele recebeu o reconhecimento com o troféu de destaque no eixo tecnológico produção cultural e design, e ainda obteve a nona dassificação geral na Mostra. Na MEP ele foi apresentado pelas alunas Samara Taciane Ott de Oliveira, Franciéli Freitas e Elivane Matozo.

Figura 3 - Reportagem sobre a premiação do Projeto Audiobooks Fonte: Jornal Noroeste (2013).

No mês de janeiro de 2013 outra novidade muito positiva em relação ao Projeto Audiobooks foi a sua escolha como finalista no $3^{\text {o }}$ Concurso Aprender e Ensinar - Tecnologias Sociais, promovido pela Revista Fórum e Fundação Banco do Brasil. Entre mais de 1.780 participantes, o projeto foi um dos 64 escolhidos para participar do Seminário Nacional sobre Tecnologias Sociais na Educação, realizado em Brasília, em fevereiro do ano de 2013.

\section{Projeto de criação de audiobooks do curso técnico em publicidade do Cairu é premiado nacionalmente}

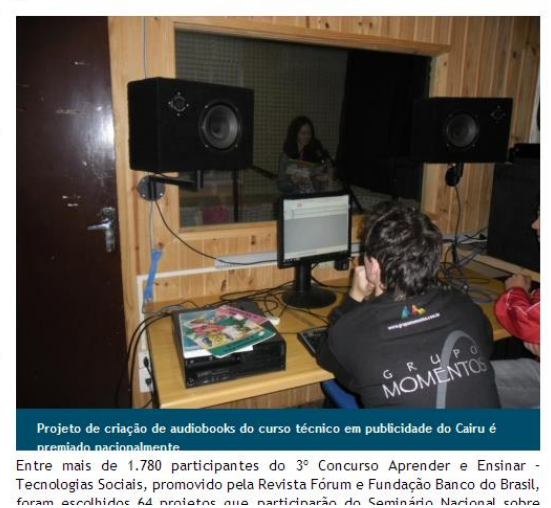

Figura 4 - Reportagem sobre a premiação nacional do Projeto Audiobooks Fonte: Jornal Noroeste (2013a) 
Em todos os momentos em que foi apresentado, o material foi muito bem recebido e, aos poucos, o projeto foi tomando uma proporção que não era esperada pelos alunos, pois a mídia da cidade procurou a escola para saber o que havia sido desenvolvido no Projeto Audiobooks. Assim, várias entrevistas foram dadas, em distintos veículos de comunicação, a respeito das atividades. Os vereadores do município também quiseram conhecer os audiobooks e convidaram o grupo para se dirigir à Câmara de Vereadores para apresentar todo o projeto.

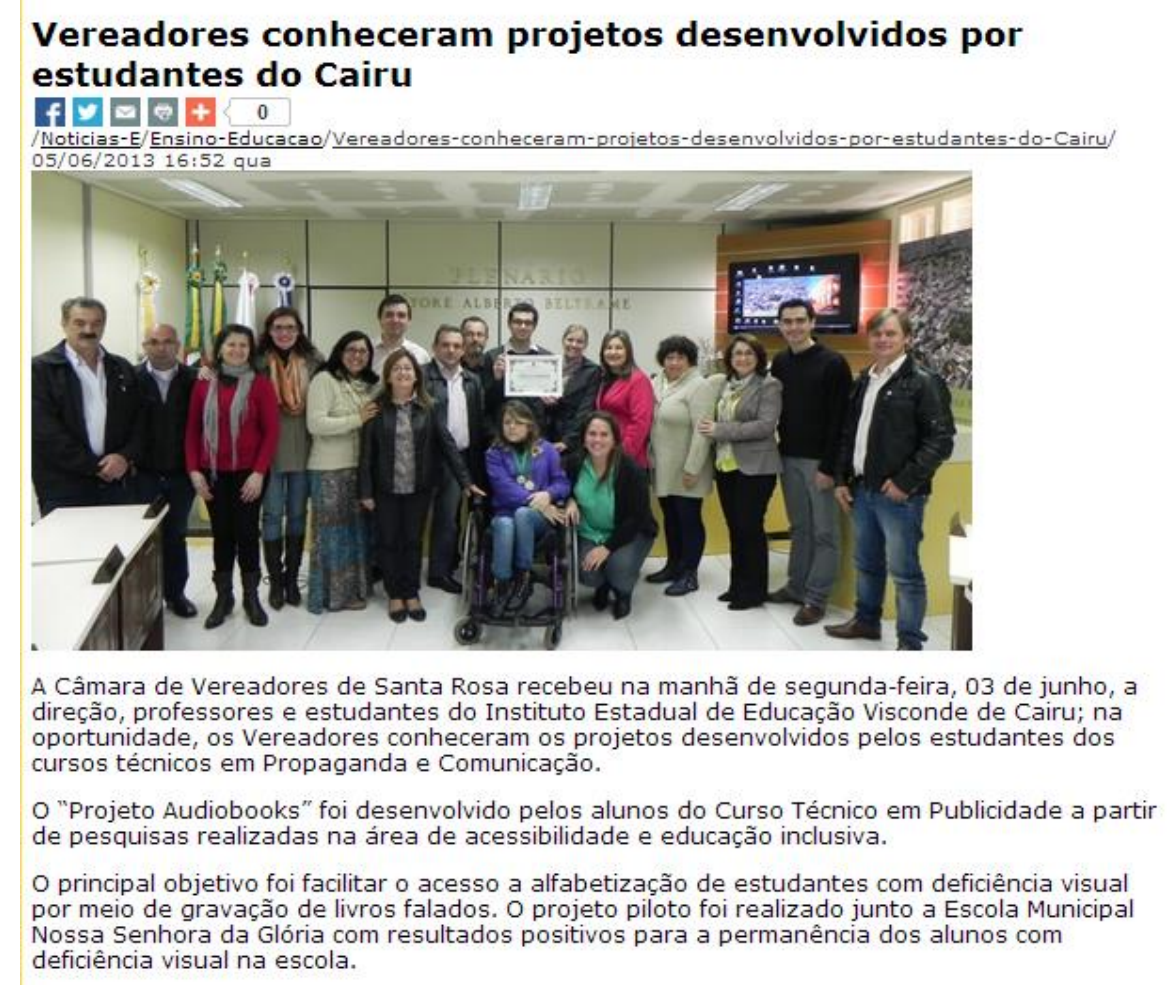

Figura 5 - Reportagem sobre a visita dos integrantes do Projeto Audiobooks à Câmara de Vereadores de Santa Rosa

Fonte: Leite Quente.com (2013).

Devido à tamanha proporção que o Projeto Audiobooks tomou, levantou-se a ideia de abranger a literatura gaúcha, pois analisando esse acervo bibliográfico digital, constatou-se a carência de disponibilidade de tais obras, em nível de estado. Os profissionais da turma de publicidade, entendendo as dificuldades das pessoas com deficiência visual, propuseram-se a disponibilizar mais conhecimento em forma de áudio, facilitando a esse indivíduo o alcance a essa forma de aprendizado.

Portanto, no momento, além do aumento da distribuição das obras já gravadas, estão em processo de desenvolvimento novos audiobooks, dessa vez de obras literárias gaúchas. Espera-se que esse projeto cresça cada vez mais, se fortaleça e ainda beneficie muitos alunos deficientes visuais.

\section{Considerações finais}

O Projeto Audiobooks foi, sem dúvida, uma iniciativa importante para trazer benefícios à inclusão de deficientes auditivos e fornecer a eles a oportunidade de serem indivíduos autônomos na construção de seu conhecimento. Logicamente, como todo projeto no qual se busca fazer um trabalho de qualidade, o caminho foi longo, muitas vezes árduo, mas, sobretudo, compensador e agregador. Muitos foram os aprendizados para todos os envolvidos, não só quanto a saberes técnico-científicos, mas conhecimentos humanísticos e éticos.

Ao longo de todo processo de desenvolvimento do Projeto Audiobooks, algo que todos os 
participantes sempre quiseram deixar bastante claro é que não haveria sentido em cursar o Técnico em Publicidade se, através dos conhecimentos adquiridos, eles não pudessem beneficiar outras pessoas e nem tornar o mundo um lugar melhor e mais justo. Acredita-se que eles possam se sentir realizados, pois, certamente, inúmeros deficientes visuais estão sendo ou serão beneficiados pelo trabalho do grupo de inclusão, em grande parte pelo trabalho deles, é, hoje, uma realidade mais próxima das escolas que receberam o material produzido.

\section{Referências}

BETTELHEIM, Bruno. A psicanálise dos contos de fada. 19 ed. Rio de Janeiro: Paz e Terra, 1980, p. 366.

BRASIL. Declaração de Salamanca sobre princípios, políticas e práticas na área das necessidades educativas especiais,1994. Disponível em: $<$ http://portal.mec.gov.br/seesp/arquivos/pdf/salamanca.pdf>. Acesso em: 10 mai. 2013.

COELHO, Silmara; CASTRO, Magali. O processo de Letramento na Educação Infantil. Pedagogia em ação, v.2, n.2, p.79-117, nov. 2010.

JORNAL NOROESTE. Projetos de Pesquisa do Cairu são premiados em Mostra. 2013.

Disponível em: <http://www.noroestenoticias.com.br/publicacao-6777Projetos_de_Pesquisa_do_Cairu_sao_premiados_em_Mostra_fire >. Acesso em: 06 jun. 2014.

JORNAL NOROESTE. Projeto de Criação de Audiobooks do Curso Técnico em Publicidade do Cairu é premiado nacionalmente. 2013a. Disponível em: $<$ http://www.noroestenoticias.com.br/publicacao-9253

Projeto_de_criacao_de_audiobooks_do_curso_tecnico_em_publicidade_do_Cairu_e_premiado_nacion almente.fire>. Acesso em: 10 jun. 2014.

JESUS, Patrícia Silva. Inclusão ponto a ponto: inclusão social da pessoa com deficiência visual através da produção escrita. Paraíba: [s.n.], 2007.

LAPLANE, Adriana Lia Friszman; BATISTA, Cecília Guarneiri. Ver, não ver e aprender: a participação de crianças com baixa visão e cegueira na escola. Cadernos Cedes, Campinas, v.28, n.75, p.209-227, mai./ago. 2008.

LEITE QUENTE.COM. Vereadores conheceram projetos desenvolvidos por estudantes do Cairu. 2013. Disponível em: <http://www.leitequente.com/Noticias-E/Ensino-Educacao/Vereadoresconheceram-projetos-desenvolvidos-por-estudantes-do-Cairu/>. Acesso em: 04 jun. 2014.

MENEZES, Nelijane C.; FRANKLIN, Sérgio. Audiolivro: uma importante contribuição tecnológica para os deficientes visuais. Ponto de Acesso, Salvador, v.2, n.3, p.58-72, dez. 2008.

NUERNBERG, Adriano Henrique. Contribuições de Vigotsky para a educação de pessoas com deficiência visual. Psicologia em Estudo, Maringá, v.13, n.2, p.307-316, abr.jjun. 2008.

RESENDE, Terezinha Cristina Campos de. Da abóbora à carruagem: a construção do letramento. Juiz de Fora, Veredas on line, v.1, p. 49-65, 2007. 
RIGLISKI, Adriane Schreiber. Contribuições da contação de histórias no desenvolvimento das linguagens na infância. 2012. 19 p. Monografia (Graduação em Pedagogia) - Universidade Regional do Noroeste do Estado do Rio Grande do Sul, Ijuí, 2012.

SANTOS, W.C.; SILVA, R.S. Auxílio ao processo de inclusão de alunos com deficiência visual como condição para uma aprendizagem de qualidade. Holos, ano 29, v.24, 2013.

SCHMIDT, Maria Helena Costa Braga; MARQUES, Maria Lúcia; COSTA, Vera Lúcia Vôos Gomes da. O processo da aquisição da leitura e da escrita na infância. In: NICOLAU, Marieta Lúcia Machado; DIAS, Marina Célia Moraes (Orgs.). Oficinas de sonho e realidade na formação do educador da infância. Campinas: Paipirus, 2003. p.193-229.

SOARES, Magda. Alfabetização e letramento na educação infantil. Revista Pátio Educação Infantil, ano VII, n.20, online, jul./out. 2009.

SOUZA, Linete Oliveira de; BERNARDINO, Andreza Dalla. A contação de histórias como estratégia pedagógica na Educação Infantil e Ensino Fundamental. Educere et Educare, v.6, n.12, p. 235-249, jul./dez. 2011. 